\title{
Preliminary evaluation of fuel oil produced from pyrolysis of low density polyethylene water- sachet wastes
}

*ADEMILUYI, T; AKPAN, C

\author{
Department of Chemical/Petrochemical Engineering, Rivers State University of Science and Technology. Port- \\ Harcourt. Nigeria
}

\begin{abstract}
Potentials of waste water sachets for the production of fuel oil were evaluated. In this work, waste polyethylene (pure water sachets) was pyrolysed at different temperatures: $130-190^{\circ} \mathrm{C}, 200-300^{\circ} \mathrm{C}$, and $300-450^{\circ} \mathrm{C}$ using a batch reactor. Below $200^{\circ} \mathrm{C}, 78 \%$ of the waste was converted to wax, $18 \%$ to fuel oil and $3 \%$ to noncondensable gases. The wax content decreases as temperature increases. The highest quantity of fuel oil was produced between $300^{\circ} \mathrm{C}-450^{\circ} \mathrm{C}$. The pyrolysis was found to increase with temperature. $86.5 \%$ of fuel oil was recovered from waste polyethylene at a reaction time of 135 minutes by pyrolysing up to $450^{\circ} \mathrm{C}$. The chromatographic analysis shows that the fuel oil produced (up to $450^{\circ} \mathrm{C}$ ) contains paraffins, isoparaffins, olefins, naphthalenes, aromatics and polyaromatics ranging from $\mathrm{C}_{3}-\mathrm{C}_{38}$.. It could be refined further to produce domestic kerosene and gasoline. The physical and structural properties of the fuel oil produced compared favorably with that of Aviation fuel JP-4 (a wide-cut US Air force fuel). Presently African countries are importing aviation fuels. The fuel oil produced from the pyrolysis of waste water sachets can therefore be used in place of JP-4, providing the aviation industry with a cheaper fuel oil from a cheaper source (waste water sachets) than crude oil. The pyrolysis of these waste water sachets will also enhance proper waste management of the menace created by the usage of these waste polyethylene sachets in our society. @JASEM
\end{abstract}

The use of low-density polyethylene for packaging treated water is on the increase in Nigeria and other West African countries. Producers of treated water prefer it, as well as the consumers because it is relatively cheaper, (4 Cent) compared with that of bottled water, which is sold for (40cent). Polyethylene films (commonly called pure water sachets in Nigeria) are therefore seen littering the cities, schools, stadium, wedding reception venues etc. During packaging of the water, lots of waste polyethylene are generated. The producers of water sachets often burn most of the waste sachets in a pit behind their companies. These polyethylene films are non-biodegradable and can remain on the ground for years. Pyrolysis is a thermal treatment process where waste is subjected to heating in an atmosphere with a deficiency of oxygen below the stoichiometric combustion level. The thermal degradation of polyethylene generates a mixture of gases, oils and waxes (Bertolini et al, 1987).

Several studies have been carried out in the past and previously on pyrolysis of polyethylene and plastics using batch reactors. Pyrolysis of waste polyethylene (PE) and polystyrene (PS) showed that waste PS yielded higher liquids while waste PE yielded higher gaseous product (Kiran et al, 2000). Font et al (2003) studied the evolution of semivolatile compounds and toxic by products in the pyrolysis of polyethylene from $600^{\circ} \mathrm{C}$ to $900^{\circ} \mathrm{C}$. Primary decomposition of the waste leads to the production of $\alpha, \omega$-olefin, $\alpha$-olefin and n-paraffin. At high temperatures above $700^{\circ} \mathrm{C}-$ $800^{\circ} \mathrm{C}$, poly-aromatic hydrocarbons were formed. Tsuji et al, (2001) gasified polyethylene, polypropylene and polystyrene plastic pellets in a two- stage thermal degradation process. The main component of the product gas for polyethylene and polypropylene were methane and olefins such as ethane and propylene with some aromatic oils as by products.

The aim of this research is to study the pyrolysis of low-density polyethylene (pure water sachets) to produce fuel oil, which will be of great economic importance and completely reduce the menace caused by littering of the film on our streets and dumpsites in Nigeria. Pure water sachet was chosen because of the increase in the volume of waste generated daily by its usage in Nigeria (Ademiluyi et al, 2004).

\section{MATERIALS AND METHODS}

MATERIALS : Waste low-density polyethylene films (pure water sachets, picked around the campus premises), Batch reactor, heater, Thermocouple, condenser, water for cooling, lagging materials, a measuring cylinder to receive the oil and weighing balance.. A reactor unit made of mild steel was constructed with an hopper and connected to a glass condenser. The reactor was adequately lagged for proper condensation of the gaseous product. The heat of reaction is supplied from a power source i.e. $220 \mathrm{~V}$, $5 \mathrm{~kW}$ A.C. mains. The cooling water used was water at $25^{\circ} \mathrm{C}$. The condensed oil was received in a measuring cylinder to monitor the rate of product formation. A thermocouple was connected to reactor to monitor the reaction temperature.

EXPERIMENTAL PROCEDURE: The pure water sachets were washed with water, dried to remove any 
dirt and waste pure water sachets were cut into smaller sizes. $100 \mathrm{~g}$ of it was weighed and passed through the hopper of the reactor. The hopper was then properly covered. Adequate precautions were put in place to make sure there is no leakage before start of experiment. The heater was then switched on and the pyrolysis continued, until the last drop of oil was noticed in the measuring cylinder. A glass condenser was connected tightly to the reactor to cool the condensing vapour from the reactor. Water at $25^{\circ} \mathrm{C}$, connected counter currently was used to cool the vapor. No catalyst was used. The volume of fuel oil produced was monitored with time and temperature. The fuel oil produced was sent immediately for analysis. The fuel oil was analyzed using two gas chromatography (Agilent GC $6890 \mathrm{~N}$ provided with a Flame ionization detector (FID) and Helium gas carrier) using a capillary silica gel column DB5 and Shimadzu GC (C11013200162K1). The physical properties of the oil were also determined using
ASTM standards and Chemical Engineering Handbook (Perry et al, 1987). The physical properties obtained were then compared with other fuel oils. The pyrolysis was also carried out at $130-190^{\circ} \mathrm{C}, 200$ $300^{\circ} \mathrm{C}$ and then 300 to $450^{\circ} \mathrm{C}$ to determine the effect of temperature on the products formed.

\section{RESULTS AND DISCUSSION}

Table 1 shows the effect of temperature on the products obtained from pyrolysis of waste. At $190^{\circ} \mathrm{C}$ and below more wax was produced with $18 \%$ oil and $3 \%$ non-condensable gaseous products. The wax content decreases with increase in fuel oil as the temperature increases. No wax was obtained at high temperature $\left(300\right.$ to $\left.450^{\circ} \mathrm{C}\right)$; black powdery carbon residue was left with some non-condensable gaseous products. $100 \mathrm{~g}$ of waste polyethylene used yielded $86.5 \mathrm{~g}(115 \mathrm{~mL})$ of fuel oil at above $300^{\circ} \mathrm{C}$.

Table 1: Products obtained from pyrolysis of waste at different temperatures

\begin{tabular}{cccccc}
\hline $\begin{array}{c}\text { Temperature } \\
{ }^{\circ} \mathrm{C}\end{array}$ & $\begin{array}{c}\text { Mass of Waste } \\
\text { polyethylene }(\mathrm{g})\end{array}$ & $\begin{array}{c}\text { Mass of } \\
\text { Fuel oil } \\
(\mathrm{g})\end{array}$ & $\begin{array}{c}\text { Mass of } \\
\text { wax } \\
(\mathrm{g})\end{array}$ & $\begin{array}{c}\text { Mass of } \\
\text { gaseous } \\
\text { products } \\
(\mathrm{g})\end{array}$ & $\begin{array}{l}\text { Mass of } \\
\text { carbon } \\
\text { residue }(\mathrm{g})\end{array}$ \\
\hline $130-190$ & 97.72 & 18.30 & 76.14 & 3.28 & 0.00 \\
$200-300$ & 96.55 & 33.28 & 55.29 & 7.68 & 0.00 \\
$300-450$ & 100.00 & 86.50 & 0.00 & 1.93 & 11.56 \\
\hline
\end{tabular}

Figure 1 shows the effect of reaction temperature and time on product yield. The product yields increases as reaction temperature increases. The product yield also increases with time. $86.5 \%$ of the wastes were converted to fuel oil for samples heated up to $450^{\circ} \mathrm{C}$ for 135 minutes. Figure 2 show chromatograms of the oil produced from the pyrolysis of waste polyethylene (pure water sachets). The fuel oil produced between $25-450^{\circ} \mathrm{C}$ was analyzed because at this temperature all the waste had been converted to fuel oil, with no wax residue as shown in Table 1. The chromatographic analysis (Figure not shown) shows that pyrolysis of the waste water sachets up to $450^{\circ} \mathrm{C}$, produced paraffins, Isoparaffins, olefins, Naphthalene, aromatics and polyaromatics ranging from $\mathrm{C}_{3}-\mathrm{C}_{34}$, with high concentration of $\mathrm{C}_{6}-\mathrm{C}_{23}$. This also indicate that the fuel oil produced is a wide cut fuel consisting of gasoline $\left(\mathrm{C}_{5}-\mathrm{C}_{10}\right)$, Kerosene $\left(\mathrm{C}_{10^{-}}\right.$ $\left.\mathrm{C}_{16}\right)$, diesel oil $\left(\mathrm{C}_{14}-\mathrm{C}_{20}\right)$ etc The branched alkanes, alkenes and aromatic hydrocarbons present reveals that the fuel oil will have excellent antiknock qualities (Morrison, 1973).

Table 2 : Polyaromatics obtained from GC analysis of the Fuel oil produced up to $450^{\circ} \mathrm{C}$

\begin{tabular}{cccl}
\hline Ret. t. (Min) & Height, (PA) & Amount, $(\mathrm{mg} / \mathrm{L})$ & Name of Polyaromatics \\
\hline 6 & - & $<0.1$ & Naphthalene \\
7 & - & $<0.2$ & 2-Methylnaphthalene \\
9 & 164.6 & 60.16 & Acenaphthylene \\
9 & 46.2 & 16.64 & Acenaphthene \\
10 & 74.4 & 26.21 & Fluorene \\
12 & 72.3 & 26.14 & Phenanthrene \\
15 & 97.5 & 35.37 & Fluoranthene \\
16 & 41.9 & 14.65 & Pyrene \\
\hline
\end{tabular}


Preliminary evaluation of fuel oil...

\begin{tabular}{lccl}
\hline 18 & 32.2 & 11.87 & Chrysene \\
18 & 10.7 & 4.04 & Benzo (a) Anthracene \\
21 & 7.5 & 3.84 & Benzo (k) Fluoranthene \\
21 & 11.5 & 6.41 & Benzo (b) Fluoranthene \\
22 & 3.4 & 2.08 & Benzo (a) Pyrene \\
27 & 3.0 & 2.89 & Benzo (ghi) Perylene \\
\hline
\end{tabular}

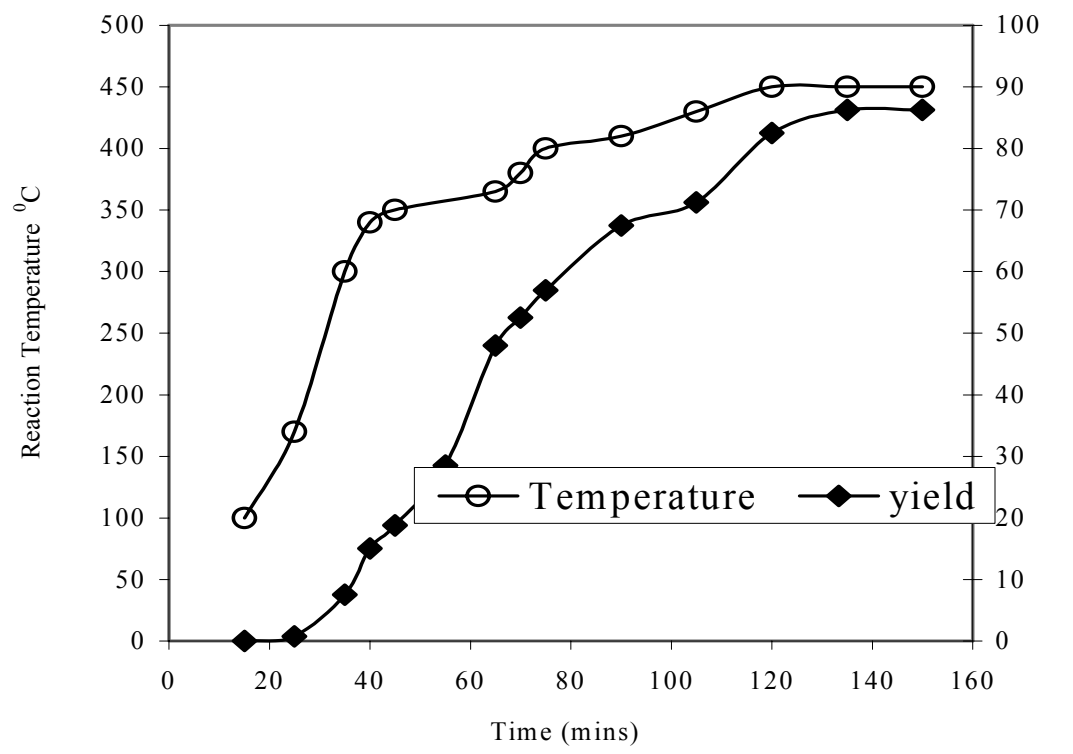

Fig 1 Effect of temperature and time on fuel oil yield (\%)

The oil was further analyzed using Agilent GC $6890 \mathrm{~N}$ to identify the heavy aliphatic hydrocarbons and polyaromatics in the fuel oil. Fig 3 shows the heavy hydrocarbons $\left(\mathrm{C}_{11}-\mathrm{C}_{38}\right)$ were present in the fuel oil. The concentration of $\mathrm{C}_{11}-\mathrm{C}_{16}$ in the fuel oil (Ret. time of $6.98 \mathrm{mins}-11.59 \mathrm{mins}$ ) was high when compared with the concentration of other heavy aliphatics .The concentration n-Nonadecane $\mathrm{C}_{19}$ was also significant. Concentration of $\mathrm{C}_{32}-\mathrm{C}_{38}$ was small compared to other aliphatic, which indicate that above $450^{\circ} \mathrm{C}$ all the waste water sachets would have been converted to fuel oil.

Table 3. Physical properties of fuel oil produced up to $450^{\circ} \mathrm{C}$

\begin{tabular}{llll}
\hline $\mathrm{S} / \mathrm{NO}$ & Properties & Quantity & Unit \\
\hline 1. & Specific gravity at $15^{\circ} \mathrm{C}$ & 0.75 & - \\
2. & API at $15^{\circ} \mathrm{C}$ & 57 & - \\
3 & Density at $15^{\circ} \mathrm{C}$ & 0.75 & $\mathrm{~g} / \mathrm{cm}^{3}$ \\
4. & Saybolt viscosity at $15^{\circ} \mathrm{C}$ & $>5.33$ & $\mathrm{cSt}$ \\
5. & Sulfur content & 0.00 & - \\
6. & Flash point & $<25$ & ${ }^{\circ} \mathrm{C}$ \\
7. & Pour point & 3 & ${ }^{\circ} \mathrm{C}$ \\
8 & Distillation range & $40-360$ & ${ }^{\circ} \mathrm{C}$ \\
9. & Water content & Trace & - \\
10 & Ash & None & - \\
11 & Heat of combustion & $2.97 \times 10^{7 *}$ & $\mathrm{KJ} / \mathrm{m}^{3}$ \\
12 & Specific heat capacity at $15^{\circ} \mathrm{C}$ & $2.09^{*}$ & $\mathrm{KJ} / \mathrm{kg}^{0} \mathrm{C}$ \\
13 & Thermal conductivity at $15^{\circ} \mathrm{C}$ & $0.155^{*}$ & $\mathrm{~W} / \mathrm{mK}^{\circ}$ \\
14 & Total carbon & 85.25 & - \\
15 & Total hydrogen & 14.75 & - \\
16 & C/H Ratio & 5.78 & - \\
\hline
\end{tabular}


Preliminary evaluation of fuel oil...

*Source: PERRY et al (1987)

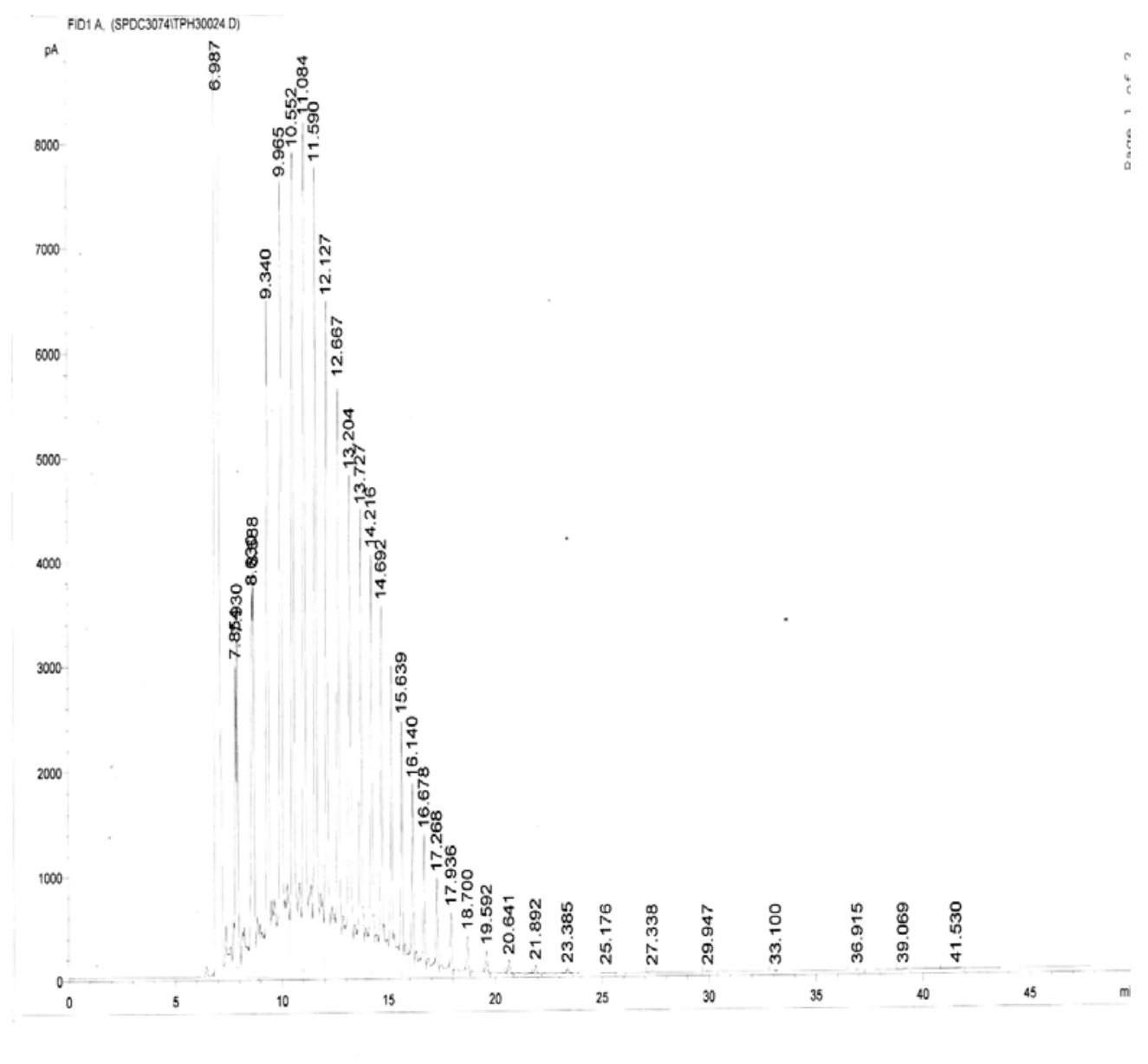

Fig 2 Chromatogram of the heavy aliphatics $\mathrm{C}_{11}-\mathrm{C}_{38}$ compounds in the fuel oil produced up to $450^{\circ} \mathrm{C}$ (using Agilent GC $6890 \mathrm{~N}$ )

Table 2 shows the polyaromatics in the fuel oil analysed using Agilent gas chromatography (GC $6890 \mathrm{~N})$. Acenaphthylene has the highest concentration. The concentration of Naphthalene and 2-Methylnaphthalene was very small. The composition and concentrations of each compound in the fuel oil produced were obtained from the chromatographic analysis and were used to calculate the total hydrocarbon in fuel oil.

Table 3 shows the physical properties of the fuel oil produced, which were determined using American standard of testing methods and standard charts for fuel oils (Perry et al, 1987). The properties of the fuel oil produced were compared with that of other fuel oils and were found to compare favorably with JP- 4 (Jet propulsion), an aviation fuel oil. JP-4 is a widecut (mixture of gasoline and kerosene) fuel oil that is used by the U.S Air force as aircraft fuels. It is also called jet fuel-4. JP-4 is a colorless to straw-colored liquid. It smells like gasoline and /or kerosene. JP-4 is flammable. Refining kerosene, a petroleum oil or shale oil can make JP-4. JP-4 is a blends of chemical made according to standards specified by the U.S. Air force for each fuel. JP-4 is liquids at room temperature, but can also change into vapor (ATDR, 1995). The comparison between the properties of the fuel oil produced up to $450^{\circ} \mathrm{C}$ and $\mathrm{Jp}-4$ are presented in Table 4. 
Table 4. Typical properties of fuel oil produced up to $450^{\circ} \mathrm{C}$ and JP 4(Aviation fuel)

\begin{tabular}{|c|c|c|c|c|}
\hline S/No & Properties & Unit & Fuel Oil produced & JP- 4 (aviation oil)* \\
\hline 1 & Hydrogen content & $\%$ & 14.75 & $>13.5$ \\
\hline 2 & Distillation range & ${ }^{0} \mathrm{C}$ & $40-360$ & $40-270$ \\
\hline 3 & API & - & 57 & $45-57$ \\
\hline 4 & Density at $15^{\circ} \mathrm{C}$ & $\mathrm{g} / \mathrm{cm}^{3}$ & 0.751 & $0.751-0.802$ \\
\hline 5 & Physical state & - & Liquid & Liquid \\
\hline 6 & Flammability & - & $\begin{array}{l}\text { Flammable } \\
\text { room Temp }\end{array}$ & Flammable \\
\hline 7 & Colour & - & $\begin{array}{l}\text { Light yellow - } \\
\text { light red }\end{array}$ & $\begin{array}{l}\text { Colorless - strawed } \\
\text { colour }\end{array}$ \\
\hline 8 & Constituent & - & $\begin{array}{l}\text { Paraffins, } \\
\text { Isoparaffins, } \\
\text { olefins, } \\
\text { Naphthlenes, } \\
\text { aromatics and } \\
\text { polyaromatics }\end{array}$ & $\begin{array}{l}\text { Paraffins, } \\
\text { Isoparaffins } \\
\text { Naphthlenes, } \\
\text { aromatics and } \\
\text { polyaromatics }\end{array}$ \\
\hline
\end{tabular}

Conclusion: The pyrolysis of waste polyethylene film to produce fuel oil increases with temperature. High yield is best obtained from above $300^{\circ} \mathrm{C}$. The fuel oil formation is also affected by the type of heat source i.e. reaction time is longer when a $2000 \mathrm{~W}$ heater was used, than when $5000 \mathrm{~W}$ was used. The physical properties of the fuel oil produced compared favorably with that of Aviation fuel JP- 4, which shows that the fuel oil can be used in place of JP- 4, which is more expensive than Kerosene. Petroleum products like kerosene, gasoline, diesel oil etc could be obtained by pyrolysing at lower temperature since the fuel oil produced contains $\mathrm{C}_{3}$ to $\mathrm{C}_{38}$. The work on refining this fuel oil to Petroleum products like kerosene, gasoline, diesel oil etc is on course. The pyrolysis of these waste sachets showed that instead of constituting a menace to the society it could serve as an energy source. $86.5 \%$ conversion was achieved during the pyrolysis without catalyst by pyrolysing up to $450^{\circ} \mathrm{C}$. The type of lagging used was found to affect the yield. Hence pyrolysis of these waste sachets does not only manage the environment but is also a means of cheaper energy source for the aviation industry and other domestic fuel users.

Acknowledgements: The authors are grateful to Prof E.N. Wami and Mr Chukuigwe for their useful criticism and suggestions.

\section{REFERENCES}

Ademiluyi, T ; Akpan, C (2004). Production of fuel oil from pyrolysis of waste polyethylene (pure water sachets). In: Nigerian Society of Chemical Engineers Conf. Proc. 34, Port Harcourt, Nigeria, p13 - 18 .
ATSDR's Toxicological profile for Jet Fuels JP - 4 and JP - 7 (1995). US Public Health Service, Atlanta GA, US.

Bertolini, G E ; Fontaine, J (1987). Value recovery from plastic waste by pyrolysis in molten salts, Conservation and Recycling, 10 :331-343.

Font, R ; Aracil, I; Fullana, A; Martin-Gullon, I ; Conesa J A, (2003). Semivolatile compounds in pyrolysis of polyethylene. J. Anal. and Applied Pyrolysis 68: 599-611.

Kiran, N; Ekinci, E; Snape, C.E. (2000). Recycling of plastic waste via pyrolysis. J Resources, Conservation and Recycling, 29: 273-283.

Morrison, R T; Boyd, R N (1973). Organic Chemistry, $3^{\text {rd }}$ Ed, Allyn and Bacon Inc. p109.

Perry, R H ; Green, D (1987). Perry's Chemical Engineers' Handbook McGraw Hill

International Editions, Japan, section 9.8 - 9.12.

Tsuji, T; Tanaka, Y; Itoh, H (2001). Two stage thermal gasification of polyolefins. J. Material Cycles and Waste Management. 3: 2-7. 